\title{
Subject and personal particularities of women having various stages of breast cancer
}

\author{
Diana A. Tsiring ${ }^{1}$, Evgenia A. Evstafeeva ${ }^{1}$, Irina V. Ponomareva ${ }^{1 *}$, Yana N. Sizova ${ }^{1}$
}

\begin{abstract}
Introduction: The relevance of the research is on the one hand associated with improvement of medical technologies for oncological diseases treatment contributing to increasing the patients' life expectancy, which leads to an increase of the actual quantity of oncological patients. On the other hand, it is due to worsening of the quality of life of patients having malignant tumors depending both on treatment methods and the patients' mental and emotional condition.

Objective: This paper is aimed at finding psychological personal determinants that create scientific bases to allow using subjective psychological factors alongside with medical practice in working with cancer patients for improving their quality of life.

Methods: The leading approach to studying this problem is the systemic and subject-based approach that allows taking an integral view of subject and personal characteristics of oncological patients. Various questionnaires focused on the coping behavior, viability and control were used as psychodiagnostic techniques for assessing the subject and personal characteristics.

Results: In the paper, a review of studies is presented that deal with psychological particularities of women having breast cancer, and psychological features women with breast cancer distinguishing them from healthy women are described. As a result of the research conducted, it has been found there are personal and subjective particularities of self-control, subjective control and viability in women having breast cancer distinguishing them from healthy women.

Conclusion: The materials of the paper are of practical importance for practicing psychologists who monitor and adjust the treatment process both in terms of oncologists and of psychological support, which gives the opportunity to adjust treatment methods up to the patient's mental and emotional condition.
\end{abstract}

Keywords: oncologic psychology, breast cancer, psychological particularities, viability, coping strategies

\section{INTRODUCTION}

Solving the problem of survivability and treatment efficiency in malignant neoplasm diseases is not only a problem of science, but also the national objective and strategic task of development of the Russian Federation.

On the one hand, improvement of medical technologies for oncological diseases treatment contributes to increasing the patients' life expectancy, which leads to an increase of the actual quantity of oncological patients. On the other hand, the quality of life of patients having malignant tumors depending both on treatment methods and the patients' mental and emotional condition worsens. So the data about psychological personal determinants create scientific bases that allow making use of subjective psychological factors alongside with medical practice in working with cancer patients for improving their quality of life.

The outlined problem shapes the relevance and social importance of tasks of this project supported by the grant of the Russian Science Foundation aimed at studying psychological factors of survivability and disease progress in patients having malignant neoplasms (RSF grant No.19-18-00426).

Solving this scientific problem will allow gaining fundamental scientific ideas about psychological factors of survivability in patients having malignant neoplasms, in particular, women having breast cancer. The authors plan to conduct a series of longitudinal studies with a sampling of women having BC who are under oncologists' supervision from the point of diagnosing. This will allow getting ideas about the dynamics of change of psychological personality features included in the complex of resistance and vitality, during the disease course and under different options of the

1 Chelyabinsk State University, Chelyabinsk, Russia.

Received: 12 Mar 2019, Accepted: 23 Aug 2019
Correspondence: Irina V. Ponomareva

Department of Psychology, Chelyabinsk State University, Chelyabinsk, Russia.

(C) 2019 by the authors; licensee Modestum Ltd., UK. This article is an open access article distributed under the terms and conditions of the Creative Commons Attribution License (http://creativecommons.org/licenses/by/4.0/). 
direct efficiency of treatment (the duration of antineoplastic effect lasting, the dynamics of sizes and quantity of tumor lesions). The disease progress particularities in mutual relation to the psychological subjective factors will enable the practicing psychologists to monitor and adjust the process, both in terms of oncologists and in terms of psychological support, which will provide the opportunity to adjust treatment methods up to the patient's mental and emotional condition.

Within the project, a comparative analysis of psychological factors in women having $B C$ that has been quiescent for 6 months and more, and in stage IV BC patients is conducted. The analysis will allow identifying a set of psychological factors contributing to the current and long-term efficiency of treatment, which, in its turn, will show their effect on the duration of recurrence-free and overall survivability. The entire bulk of the obtained data about psychological factors promotes the development of oncological psychology and is a scientific base for practical recommendations for psychological services rendering psychological support of treatment of patients having malignant neoplasms, as well as for the initiative with legislative bodies in the field of healthcare for including compulsory psychological and psychotherapeutic aid into the cancer patients treatment protocol.

Today the authors present only some of the results obtained during implementation of the project and associated with studying the psychological particularities of women having breast cancer. Breast cancer is known to be the most widespread oncological disease in women. According to the statistics data, $20 \%$ of the total quantity of female patients with malignant neoplasms are women having breast cancer. It is for this reason that this category of women became the focus of the authors' attention.

\section{LITERATURE REVIEW}

The psychological parameters in patients having various types and modifications of oncological diseases have been studied for several decades already. Nevertheless, worldwide, scientists' interest in this topic has not only remained steady but has been growing. The considerable quantity of studies in this domain show a high percentage of impact of psychological factors on the progress of the disease and its outcome (survivability). In spite of the increasing interest in this problem, the range of psychological phenomena studied within the sphere is quite limited. There are widespread studies of anxiety (1,2), depression (3,4), helplessness and hopelessness (5-9) as a response to the disease. Research of this kind has a serious limitation in the fact it is impossible to verify the hypothesis about these phenomena having a situation-related or a stable (personal) nature in patients, as there is no initial statistics (before the disease onset). A sufficient quantity of works deal with positive phenomena as resources for overcoming the disease. In particular, they study the level of hope for convalescence in patients having oncological diseases (10-12), coping strategies (13-15), subjective well-being $(16,17)$, metacognitive beliefs $(18)$, optimism $(19,20)$, morale (5), positive thinking (21).

In Russia, the scope of completed research into this problem is much narrower than in Europe and the USA. In the Russian psychology, this problem is largely at the initial stage of development, which is confirmed by the prevailing quantity of theoretical reviews $(22,23)$. In the recent years, works have been published that consider cancer as a consequence of post-traumatic stress (24,25), studying the attitude to the disease (26-28), as well as the interrelation between anxiety, coping strategies and defense mechanisms $(13,29,30)$. However, the Russian science makes attempts to view the psychological aspects of patients having oncological diseases in an integral way, as a system. For example, positive phenomena (authenticity, trust to oneself, optimism, viability, responsibility) are studied in mutual relation to the values- and meaning-related sphere of patients (31). Such integrated studies are of interest and require further development.

Thus, the shortage of consistent research into psychological factors of the disease course conducted along the lines of longitudinal studies can be stated. In the Russian science, questions about psychological factors contributing to survival of patients throughout a prolonged period of time have not been posed.

\section{RESEARCH METHODOLOGICAL FRAMEWORK}

The problem of this scientific project consists in analyzing the psychological particularities of women having breast cancer at various stages of the disease.

With regard to this, the objective of the research was to identify subject and personal particularities of women having breast cancer. 


\section{Research Hypothesis}

Women having breast cancer have subject and personal features distinguishing them from healthy women who have not been diagnosed with the disease.

\section{Research Sampling}

The empirical research was conducted from April 22, 2019 through June 23, 2019. 45 Russian women aged 25 to 60 took part in the research.

Group 1 of the tested ones includes 22 women having malignant tumors originating from the mammary tissue epithelium (breast cancer) of stages I, II with moderately differentiated variant of the tumor, hormone-dependent, residing within the city of Chelyabinsk and Chelyabinsk Region and being in inpatient treatment at the State budgetfunded institution of healthcare "Chelyabinsk Regional Clinical Center For Oncology and Nuclear Medicine" from the point of diagnosing and up to 6 months.

Group 2 is 23 healthy women having no history of oncological and psychiatric diseases, no complaints of their condition of health as of the point of examination, and residing within the city of Chelyabinsk and Chelyabinsk Region.

\section{Research Methods}

The subject and personal characteristics were assessed using the following techniques:

1. Questionnaire "Ways of coping behavior" by R. Lazarus as adapted by T.L. Kryukova (32). The questionnaire is used in order to identify coping mechanisms, ways of overcoming difficulties, in particular, the coping strategies for overcoming the disease situation in patients having malignant neoplasms.

2. The viability test (Hardiness Survey, S. Maddi as adapted by D. Leontyev (33)). This technique allows assessing the cancer patients' system of beliefs about themselves, the world, relation to it that enable people to endure and efficiently overcome stress situations.

3. The subjective control questionnaire test (J. Rotter, as adapted by E.F. Bazhin, S.A. Golynkin, and A.M. Etkind) measures individual particularities of subjective control over various life situations in cancer patients (according to A.A. Rean (34)).

\section{Tasks of the Research}

1. Conducting an empirical research of indices of subject and personal characteristics in the groups under study, presenting descriptive statistics;

2. Conducting the comparative analysis of subject and personal characteristics between women having $B C$ and healthy women.

3. Presenting the qualitative analysis of statistically significant distinctions of subject and personal characteristics between women having $B C$ and healthy women.

\section{RESULTS AND DISCUSSION}

In order to verify the research hypothesis, the psychological variables have been diagnosed in the women having BC and the healthy women. Table 1 lists the average values of psychological parameters under study for which statistically significant distinctions between the group of women having BC and the healthy women group have been obtained. The strategy of self-control implies attempts to overcome negative feelings related to the problem by means of intended suppression and inhibition of emotions, minimizing their influence on evaluation of the situation and selection of a behavior strategy, a high control of behavior and a strive to self-possession. High figures of the self-control strategy are observed in the BC patients group while the healthy women have an average index (13-18 - the high index, 7-12 - the average index). Indices that are above average in the group of women having $B C$ and below average in the group of healthy women are those of general internality (the maximum value is 44 , the minimum one is 0 ). The women having $B C$ are characterized by the failures-related internality indices that are above average (the maximum value is 12 , the minimum one is 0 ). Involvement rests at the medium level in the women having BC (the standard average value is 37,64 ) and it is lower than the medium in the healthy women. This component which is an individual's persuasion of the fact that one's being involved into what is happening gives one the highest chance to find something worthy is more developed in the women having BC. As for control, it is at the medium level in the $B C$ patients group, too, with the group of healthy women featuring it below the average (the standard average value is 29.17). The values of viability parameter 
Table 1: Descriptive statistics results of the subject and personal feature indices in the groups under study

\begin{tabular}{lcccccc}
\hline & Self-control & General internality & $\begin{array}{c}\text { Internality in } \\
\text { relation to failures }\end{array}$ & Involvement & Control & Risk taking \\
\hline Women having breast cancer & 14.2 & 25 & 8.2 & 37 & 29 & 17.5 \\
\hline Women deemed healthy & 11.6 & 12 & 5.1 & 24 & 23 & 13.4 \\
\hline
\end{tabular}

Source: authors

Table 2: Results of the comparative analysis of the subject and personal features between the women having $B C$ and the healthy women

\begin{tabular}{cccccccc}
\hline & Self-control & General internality & $\begin{array}{c}\text { Internality in } \\
\text { relation to failures }\end{array}$ & Involvement & Control & Risk taking \\
\hline $\mathrm{U}$ & 72 & 77 & 82.5 & 67 & 90.5 & 64.5 \\
\hline $\mathrm{P}$ & 0.004 & 0.007 & 0.019 & 0.001 & 0.014 & 0.001 \\
\hline
\end{tabular}

Source: authors

"risk taking" are higher than the average value in the BC patients while the healthy ones have it at the medium level (the standard value is 13.91).

In Table 2, the results of the comparative analysis of the subject and personal characteristics between the women having $B C$ and the healthy women are given.

With Mann-Whitney U-test, significant distinctions have been found between the groups in the extent of intensity of self-control as a coping strategy $(p<0.01)$. Higher indices of self-control in the women having BC confirm the particularity of their behavior in a problem situation, difficult for individuals, to which the authors refer a woman's having malignant neoplasm. The high self-control is a characteristic way for overcoming stress in the women having BC that gives evidence about the patients' mental disadaptation under stress conditions. Frequently, such behavior is indicative of one's fear of self-revelation, excessive self-exactingness leading to super-control of one's behavior. In the group of healthy women, this index is at the average level, which confirms the adaptive potential of personality.

In the women having BC, the values of general internality and internality in relation to failures $(p<0.01)$ (see Table 2) are statistically validly higher. The above average index according to this scale in the women having $B C$ corresponds to a higher level of subjective control over any significant situation as compared to the below average level observed in the group of healthy women. Women having BC may believe that the majority of important events in their lives have been the result of their own efforts, that they can control them and, therefore, undertake the responsibility for their lives as a whole.

The low index of the healthy women group points to a low subjective control level. They do not see the association between their actions and significant events that they consider to be a result of chance or other people's actions.

The above average values in the scale of internality in relation to failures in the women having BC speak for a developed feeling of subjective control toward negative events and situations, which is manifested in their inclination to blame themselves for various troubles and failures.

The healthy women have lower than average values of internality in relation to failures. They may ascribe responsibility for failures to other people or consider them to be a result of bad luck.

Significant distinctions have also been found between the groups according to the viability indices $(p<0.01)$. According to D. Leontyev (33), viability represents a system of one's beliefs about oneself, the world, relations with it that enable one to endure and efficiently overcome stress situations. As compared to the healthy women group, in the BC patients, statistically valid increases of values are registered in such indices of viability as involvement, control, and risk taking $(p<0.01)$ (Table 2).

Involvement is validly higher in the women having $B C$ than in the healthy women. The feeling of confidence of themselves and of the world being generous is inherent in the BC patients. The values below average registered in the group of healthy women may be indicative of the feeling of being cast-off, perceiving oneself to be "outside" the life.

Control as a viability component is better developed in the women having BC, which gives evidence about their being persuaded that fighting allows influencing the result of what is happening, even if the influence is not absolute and success is not guaranteed.

Women having breast cancer have the viability component of "risk taking" better developed than healthy women do. Women having breast cancer are convinced that everything happening to them contributes to their development. They actively absorb knowledge from experience, regardless of it being positive or negative one, and use it subsequently. 
Owing to their high risk taking, women having breast cancer can be prepared to act in a difficult situation, lacking any reliable guarantees of success, at their own risk and peril.

It can be supposed that marked viability in the women having breast cancer enables them to endure and overcome the disease situation. The intensity of all the three components of viability is important for keeping health and optimum working capacity and activity level of an individual under stress conditions. Meanwhile, it is the high self-control that gives evidence about mental disadaptation of the women having breast cancer in the disease situation.

As a result of the comparative analysis according to the remaining psychological parameters under study, no statistically significant distinctions between the groups have been found. At this stage of the research, the generalized positive expectations (optimism) or generalized negative expectations as for the future shared by women having breast cancer do not differ from the healthy women's expectations. Similarly, no differences in the extent of severity of personal helplessness, in the subjective perception of physical and mental health, in the ideas about biological and psycho-social resources (subjective age), and cognitive beliefs have been found.

\section{CONCLUSION}

Proceeding from the above, it can be noted that women having breast cancer feature psychological particularities distinguishing them from healthy women.

For women having breast cancer, a high self-control is characteristic which gives evidence about their marked disadaptation when in the disease situation. In women having BC, the trend of concealing their feelings and intentions in relation to the problem situation from the people around them may be observed. The obtained results agree with the higher values of general internality and internality in the area of failures found in women having BC. Excessive selfexactingness and the subsequent super-control of behavior are possibly related to the women's persuasion about the majority of important events in their lives resulting from their own actions. For them, a developed feeling of subjective control toward negative events and situations is characteristic, which is manifested in their inclination to blame themselves for various troubles and failures.

Meanwhile, women having breast cancer feature marked components of viability (involvement, control, risk-taking) that may prevent the inner strain from arising in a disease situation by means of persistent coping, stress-coping strategies and perceiving them as less important.

Based on the data obtained, it can be supposed that the psychological factor of emergence of breast cancer can be such a stable personal feature as a marked subjective control toward most events in one's life, including the negative events and situations which is manifested in one's inclination to blame oneself for various troubles and failures. These parameters are more pronounced in women having breast cancer than in healthy women. This assumption requires further investigation.

It should be noted that the results obtained by the authors do not agree with earlier American studies of the socalled cancer-prone person (type $C$ personality) - one that is characterized by submission, a feeling of helplessness and hopelessness (7). The concept of cancer-prone personality was criticized due to the lack of valid empirical data (35).

The diagnosed psychological variables (viability, coping strategies, subjective control etc.) were diagnosed by the authors at the beginning of the disease. So, at this stage, the question of whether they have an amplifying effect on other risk factors in line with the cascade principle or they matter on their own is difficult to answer. For this purpose, the authors plan to assess the disease development dynamics, psychological features of women having breast cancer, and to study their interrelations.

The data obtained will allow expanding the currently relevant in science ideas about patients with malignant neoplasms and contributing to studying the psychological factors of survivability and disease progress in cancer patients.

Based on the data obtained, it can be supposed that psychological characteristics that are stable personal features may be factors of emergence of the disease in women having breast cancer. This assumption requires further research.

\section{ACKNOWLEDGEMENTS}

The research has been conducted due to the grant provided by the Russian Science Foundation (project No.19-1800426). 


\section{REFERENCES}

1. Leventhal $H$, Meyer $D$, Nerenz $D$. The common sense representation of illness danger. Contributions to medical psychology, 1980;2:7-30.

2. Easterling DV, Leventhal $\mathrm{H}$. Contribution of concrete cognition to emotion: neutralsymptoms as elicitors of worry about cancer. Journal of Applied Psychology, 1989;74:787-96. https://doi.org/10.1037/0021-9010.74.5.787

3. Spiegel D. Depression and cancer: mechanisms and disease progression. Biological Psychiatry, 2003;54(3):26982. https://doi.org/10.1016/S0006-3223(03)00566-3

4. Korfage IJ, Essink-Bot ML, Janssens AC, Schröder FH, de Koning HJ. Anxiety and depression after prostate cancer diagnosis and treatment: 5-year follow-up. British Journal of Cancer, 2006;94:1093-8. https://doi.org/10.1038/sj.bjc.6603057 PMid:16622434 PMCid:PMC2361242

5. Greer S, Morris T, Pettingale KW, Haybittle JL. Psychological response to breast cancer and 15 year outcome. Lancet, 1990;335:49-50. https://doi.org/10.1016/0140-6736(90)90173-3

6. Watson $\mathrm{M}$, Haviland J, Greer S. Influence of psychological response on survival in breast cancer: a population based cohort study. Lancet, 1999;354:1331-6. https://doi.org/10.1016/S0140-6736(98)11392-2

7. Temoshok L. Personality, coping style, emotion and cancer: towards an integrative model. Cancer surveys, 1987;6(3):545-67.

8. Garssen B. Psychological factors and cancer development: evidence after 30 years of research. Clinical Psychology Review, 2004;24:315-38. https://doi.org/10.1016/j.cpr.2004.01.002 PMid:15245834

9. Ponomareva IV, Sizova YN, Tsiring DA. Structural organization of the regulatory function of a subject with different types of personal helplessness. International Journal of Civil Engineering and Technology, 2018;9(11):1822-31.

10. Folkman S. Stress, coping, and hope. Psychological aspects of cancer: A guide to emotional and psychological consequences of cancer, their causes and their management. London: Springer; 2010.

11. Benedict C, Penedo FJ. Psychological interventions in cancer. Psychological aspects of cancer: A guide to emotional and psychological consequences of cancer, their causes and their management. London: Springer science; 2013. https://doi.org/10.1007/978-1-4614-4866-2_14

12. Holland J, Lewis Sh. The human side of cancer: living with hope, coping with uncertainty. New York: Harper Perennial; 2001.

13. Moskovchenko DV. Coping behavior of women having oncological diseases of reproductive system: thesis of PhD. Moscow: M. V. Lomonosov Moscow State University; 2016.

14. Zapesotskaya IV. Social and psychological determinants of coping behavior in oncologic patients (using the example of breast cancer patients). Clinical and medical psychology: research, training, practice: a digital scientific journal, 2016;1(11). Available at: http://medpsy.ru/climp

15. Sirota NA, Fetisov BA. Coping behavior of women having breast cancer. In: Materials of the International scientific and practical conference "Relevant questions of psychology". Krasnodar, 2012:203-9.

16. Diener E. Subjective well-being. Psychological Bulletin, 1984;95(3):542-75. https://doi.org/10.1037/00332909.95.3.542 PMid:6399758

17. Cummins RA, Li N, Wooden M, Stokes M. A demonstration of set-points for Subjective Wellbeing. Journal of Happiness Studies, 2013;15(1):183-206. https://doi.org/10.1007/s10902-013-9444-9

18. Thewes $B$, Bell ML, Butow P. Fear of cancer recurrence in young early-stage breast cancer survivors: the role of metacognitive style and disease-related factors. Psychooncology, 2013;9:2059-63. https://doi.org/10.1002/pon.3252 PMid:23408595

19. Carver CS, Pozo C, Harris SD, Noriega V, et al. How coping mediates the effect of optimism on distress: A study of women with early stage breast cancer. Journal of Personality and Social Psychology, 1993;65:375-390. https://doi.org/10.1037/0022-3514.65.2.375 PMid:8366426

20. Arpentyeva MR. Psychological aspects of oncological diseases: life affirmation vs. life negation. Medical psychology in Russia: a digital scientific journal, 2016;4(39):256-63.

21. Mendelevich VD, Mendelevich DM. Positive psychotherapy in integral treatment of oncologic patients. Contemporary methods of diagnosing and treatment. Kazan, 2003:79-81.

22. Shirokova I, Prozherina Yu. Breast cancer: experts' view. Nosologies, 2016;10:53-8.

23. Semiglazova TY, Tkachenko GA, Chulkova VA. Psychological aspects of treating cancer patients. Malignant tumors, 2016;4(1):54-8. 
24. Tarabrina NV, Vorona OV, Kurchakova MS, Padun MA, Shatalova NE. Oncopsychology: post-traumatic stress in breast cancer patients. Moscow: Publishing house of the RAS Institute of psychology; 2010.

25. Kharlamenkova NE, Vorontsov SA. A life-threatening disease and its long-term psychological effects. Bulletin of NA. Nekrasov KSU, 2016;4:146-50.

26. Popov TM, Chulkova VA. Attitude to treatment and types of responding to the disease in cancer patients under systemic therapy methods. Science and education today, 2017;6(17):108-11.

27. Vagaitseva MV, Chulkova VA, Karpova EB, Leonenkova SA. Psychological research in oncology. Bulletin of SUrSU. Series "Psychology", 2015;8(3):28-35.

28. Yaltonskiy VM, Bogdanova LS. Subjective perception of the disease as a threat in prostate cancer patients. Collection of materials of All-Russian scientific and practical conference with international participation, 2011:101-5.

29. Caloudas SG. Personality, coping, and quality of life in early stage breast cancer survivors (Order No. 3410769). ProQuest Dissertations \& Theses A\&I. (519152515). 2011. Available at: http://search.proquest.com/docview/519152515?accountid $=175014$

30. Freeman-Gibb L. The relationship of illness representations and coping to fear of recurrence in breast cancer patients (Order No. 3530607). 2012. Available at: http://search.proquest.com/docview/1125511174?accountid= 175014

31. Evnina KYu. Psychological regulation of cancer patients: a view of positive psychology. Contemporary problems of science an education, 2014;6:1527-37.

32. Kryukova TL. Methods of studying the coping behavior: three coping scales. Kostroma: N. A. Nekrasov KSU. Avantitul publishers; 2010.

33. Leontyev DA, Rasskazova El. Viability test. Moscow: Smysl; 2006.

34. Rean AA. Practical psychological assessment of personality: a study guide. St. Petersburg: Publishing house of $\mathrm{SPb}$. University; 2001.

35. Soellner W. Mind and cancer: do psychosocial factors cause cancer or affect the progress of an oncological disease? Consulting psychology and psychotherapy, 2014;1:24-39. 